\title{
Impact of Team Familiarity in the Operating Room on Surgical Complications
}
A. Kurmann $1, *$

Email anita.kurmann@insel.ch

S. Keller 2

F. Tschan-Semmer 2

J. Seelandt 2

N. K. Semmer 3

D. Candinas 1

G. Beldi 1

Email guido.beldi@insel.ch

1 Department of Visceral Surgery and Medicine, Inselspital University Hospital Bern and University Bern, 3010 Bern, Switzerland

2 Institute of Work and Organizational Psychology, University of Neuchâtel, Neuchâtel, Switzerland

3 Institute of Psychology, University of Bern, Bern, Switzerland

\section{Abstract}

\section{Background}

The quality of surgical performance depends on the technical skills of the surgical 
team as weıl as on non-tecnnicaı sk1ııs, inciuaing teamwork. I ne present stuay evaluated the impact of familiarity among members of the surgical team on morbidity in patients undergoing elective open abdominal surgery.

\section{AQ1}

\section{Methods}

A retrospective analysis was performed to compare the surgical outcomes of patients who underwent major abdominal operations between the first month (period I) and the last month (period II) of a 6-month period of continuous teamwork (stable dyads of one senior and one junior surgeon formed every 6 months). Of 117 patients, 59 and 58 patients underwent operations during period I and period II, respectively, between January 2010 and June 2012. Team performance was assessed via questionnaire by specialized work psychologists; in addition, intraoperative sound levels were measured.

\section{Results}

The incidence of overall complications was significantly higher in period I than in period II (54.2 vs. $34.5 \% ; P=0.041$ ). Postoperative complications grade $<3$ were significantly more frequently diagnosed in patients who had operations during period I (39.0 vs. $15.5 \% ; P=0.007$ ), whereas no between-group differences in grade $\geq 3$ complications were found ( 15.3 vs. $19.0 \% ; P=0.807)$. Concentration scores from senior surgeons were significantly higher in period II than in period I $(P=0.033)$. Sound levels during the middle third part of the operations were significantly higher in period I (median above the baseline $8.85 \mathrm{~dB}$ [range $4.5-11.3 \mathrm{~dB}$ ] vs. $7.17 \mathrm{~dB}$ [5.24-9.43 dB]; $P<0.001)$.

\section{Conclusions}

Team familiarity improves team performance and reduces morbidity in patients undergoing abdominal surgery.

\section{Electronic supplementary material}


The online version of this article (doi:10.1007/s00268-014-2680-2) contains supplementary material, which is available to authorized users.

\section{Introduction}

The quality of surgical performance depends not only on the technical skills of the surgical team but also on good collaboration and effective teamwork. The operating room is a very complex environment and is associated with significant morbidity: up to $60 \%$ of all adverse events occur in the operating room, with up to $33 \%$ resulting in permanent disability and up to $13 \%$ resulting in deaths [ $1-3]$. Surgeries may therefore be even more vulnerable to suboptimal teamwork than other fields. Previous work demonstrated that noise levels, which are a potential indicator of team activity, are associated with postoperative complications [4].

The introduction of checklists has influenced teamwork by structuring some processes in the operating room at the beginning of a procedure $[5,6]$. Nonetheless, other studies identified breakdowns in collaboration during critical situations that were noticeable to external observers [7,8]. Interactions among members of the surgical team may be subtle, and they occur throughout the duration of an operation. Thus, there seems to be a need to optimize interactions among members of a surgical team throughout an operation in order to improve team performance and reduce patient morbidity.

The aim of the present study was to assess whether close collaboration reduces the incidence of surgical complications. In particular, we hypothesized that team familiarity (common experience as team members) between one senior and one junior surgeon (fellowship teams) improves team performance and thereby reduces the risk of postoperative complications in patients undergoing open abdominal surgery.

\section{Methods}

\section{Patients}

A total of 117 patients undergoing elective major abdominal surgery between January 2010 and June 2012 were included in this case-control study. The inclusion criterion 
was an elective open abdominal operation performed by one of the stable dyads composed of one senior and one junior board-certified surgeon. The exclusion criteria were laparoscopic and emergency procedures and pre-existing surgical site infection (SSI). All patients who underwent operations during the specific periods and who met the inclusion criterion were analyzed. Data were prospectively collected and stored in an electronic database. Postoperative patient care visits were performed daily during the hospital stay. All patients were contacted by study nurses 30 days or more after surgery to complete a standard questionnaire to detect SSIs according to guidelines from the Centers for Disease Control and Prevention [9]. If a patient was diagnosed with a suspected SSI, consultants or general practitioners were asked to confirm the finding and to classify the SSI. This study has been reviewed and approved by the Internal Review Board of the University Hospital Bern, Bern, Switzerland.

\section{Teams and psychological assessment}

A fellowship system was introduced in 2008 at the Department of Visceral Surgery and Medicine, University Hospital Bern. Fellowship teams consist of one senior and one junior board-certified surgeon and are newly formed every 6 months, starting in January or July. During these 6-month periods, elective operations, preoperative and postoperative patient care visits, and outpatient follow-ups are performed by the fellowship team. Five senior surgeons led 16 fellowship teams. Period I was defined as the first month of each 6-month teamwork period, and the last month of each period was designated period II.

For a total of 26 operations (16 operations in period I and 10 operations in period II), every member of the surgical team completed a standardized questionnaire. This was done before staff left the operating room in order to evaluate the quality of teamwork and to report the difficulty level of the operation. Questionnaires were designed by specialized work psychologists and were confidential. Team members responded to questions about the perceived difficulty of the operation, stress during the operation, quality of team collaboration within the surgical team, and the ability to concentrate on the operation. Single items were assessed with a 7-point Likert scale in which a score of 1 indicated disagreement and a score of seven indicated full agreement. The cut-off for categorical variables was set by the mean value of each item. Analyses were run separately for questionnaire values of the entire surgical teams and of the senior 
surgeons (team leaders) responsible for the operation.

\section{Measurements of sound levels}

Intraoperative sound levels were recorded during 26 surgical procedures in two operating rooms of the same size with identical equipment, as described previously [4]. A sound-level measuring device (PCE 353, PCE GmbH \& Co.KG, Meschede, Germany) was placed directly above the operative field in a fixed holder on the operative lamp. The noise intensity was registered digitally every second in decibels $(\mathrm{dB}[\mathrm{A}])$. To eliminate the influence of general background noise, the baseline was set to the lowest decibel level measured during surgery for each patient. Results are given in medians above the baseline [4].

The operative time of each procedure was divided into three parts: first third: resection, middle third: reconstruction, and last third: closure. The middle third of each operation was defined as crucial for evaluating teamwork; this part of the operation includes highly difficult steps, such as reconstruction and close teamwork between the junior and senior surgeons. Whereas during the first and the last third of the operation the senior surgeon was not always present.

\section{Surgical technique}

All patients received preoperative antibiotic prophylaxis. Before incision, a team timeout procedure using a standardized checklist was performed [10]. Hepatobiliary and pancreatic resections were performed with a transverse upper laparotomy, and surgeries of the upper and lower gastrointestinal tract were performed with a median laparotomy. The underlying disease defined the extent of resection. In all patients, abdominal closure was performed with a running suture of PDS (polydioxanone) Loop (Ethieon Sàr1, NetrehatetEthicon Sarl, Neuchâtel, Switzerland).

Complications were classified based on the type of therapy required to treat the complication and were defined as grade $<3$ or grade $\geq 3[11,12]$. Surgical site infections that occurred up to 30 days after surgery were assessed according to the criteria developed by the U.S. Centers for Disease Control and Prevention [9]. Superficial SSI involved only the skin and subcutaneous tissue and excluded stitch abscesses. Deep SSI involved deeper soft tissues, such as the fascia and muscle, at the 
site of incision. Organ-space SSIs involved any organ or space.

\section{Outcome parameters}

The primary outcome parameter of this study was the number of overall postoperative complications that occurred in patients who underwent operations during period I or period II within one 6-month period of fellowship teamwork. Secondary outcome measures were SSI, assessment of team performance, intraoperative sound levels, duration of operation, and hospitalization time.

\section{Statistical analysis}

Univariate analysis was performed with Fisher's exact test for categorical variables. Continuous variables were compared with Student's $t$ test and are presented as medians and ranges. Two-way analysis of variance (ANOVA) was performed to analyze sound levels during the operation. $P$ values were two-sided, and $P<0.05$ was considered the threshold for statistical significance (NCSS 2007 for Windows; NCSS, Kaysville, UT).

\section{Results}

The present study included 59 patients who underwent operations during period I and 58 patients who had operations during period II. Complete follow-up information was obtained for 115 patients (98.3\%); two patients died during the 30-day follow-up because of multi-organ failure. The baseline characteristics of the two patient groups were comparable (Table 1). Operative procedures classified as "other" included adrenalectomy, multivisceral resection, retroperitoneal resection, and ventral hernia repair, including adhesiolysis. No between-group differences were found in the median duration of hospital stay (period I: 11 days; range 4-51 days; period II: 12 days, range 4-56 days; $P=0.524)$.

\section{Table 1}

Baseline characteristics and operative procedures

\begin{tabular}{|l|l|l|l|}
\hline & Period I $\boldsymbol{n}=\mathbf{5 9}$ & Period II $\boldsymbol{n}=\mathbf{5 8}$ & $\boldsymbol{P}$ value* $^{*}$ \\
\hline Age, years $^{\mathrm{a}}$ & $61(22-93)$ & $61(27-89)$ & $0.261^{\mathrm{b}}$ \\
\hline Male oender & $\mathbf{3 4 ( 5 7 . 6 )}$ & $35(603)$ & 0.851 \\
\hline
\end{tabular}




\begin{tabular}{|c|c|c|c|}
\hline . & $\cdots+\cdots$ & $\ldots(\cdots$, & $\cdots$ \\
\hline Female gender & $25(42.4)$ & $23(39.7)$ & \\
\hline $\operatorname{BMI}\left(\mathrm{kg} / \mathrm{m}^{2}\right)^{\mathrm{a}}$ & $23(16.1-42)$ & $23.6(17.3-46.8)$ & $0.535^{\mathrm{b}}$ \\
\hline ASA score ${ }^{a}$ & $3(1-3)$ & $3(2-4)$ & $0.065^{\mathrm{b}}$ \\
\hline Diabetes & $13(22.0)$ & $6(10.3)$ & 0.131 \\
\hline CVD & $17(28.8)$ & $15(25.9)$ & 0.836 \\
\hline COPD & $9(15.3)$ & $13(22.4)$ & 0.353 \\
\hline Malignant disease & $46(78.0)$ & $47(81.0)$ & 0.820 \\
\hline \multicolumn{4}{|l|}{ Type of surgery } \\
\hline Hepatobiliary/pancreas & $35(59.3)$ & $33(56.9)$ & 0.852 \\
\hline Upper GI & $5(8.5)$ & $6(10.3)$ & 0.762 \\
\hline Lower GI & $11(18.6)$ & $9(15.5)$ & 0.806 \\
\hline Other & $8(13.6)$ & $10(17.2)$ & 0.617 \\
\hline Blood loss, $\mathrm{ml}^{\mathrm{a}}$ & $300(10-5,500)$ & $500(50-3,000)$ & $0.661^{b}$ \\
\hline Duration of operation, $\min ^{\mathrm{a}}$ & $240(90-570)$ & $265(90-660)$ & $0.082^{b}$ \\
\hline \multicolumn{4}{|c|}{ Values in parentheses are percentages unless indicated otherwise } \\
\hline \multicolumn{4}{|c|}{$\begin{array}{l}B M I \text { body mass index, } A S A \text { American Society of Anesthesiologists, } C V D \text { cardiovascular } \\
\text { disease, } C O P D \text { chronic obstructive pulmonary disease, GI gastrointestinal tract }\end{array}$} \\
\hline \multicolumn{4}{|c|}{ * Fisher's exact test unless indicated otherwise } \\
\hline \multicolumn{4}{|l|}{${ }^{a}$ Values are medians (range) } \\
\hline bStudent's $t$-test & & & \\
\hline
\end{tabular}

A significantly higher incidence of overall complications was detected during period I than during period II (54.2 vs $34.5 \% ; P=0.041$; Table 2 ). The grading of complications is shown in Table 3 . The incidence of SSI was significantly higher in period I than in period II (40.7 vs. $22.4 \% ; P=0.046)$. Incisional superficial SSI occurred in 16 patients $(27.1 \%)$ who underwent operation during period I and in 6

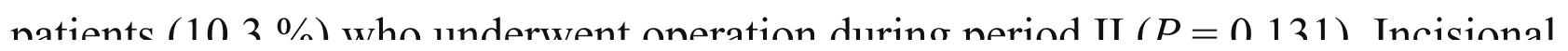


deep SSI occurred in one patient in each group (1.7 vs. $1.7 \% ; P=1.000)$, and organspace SSI was diagnosed in nine patients in each group (15.3 vs. $15.5 \%$; $P=1.000)$.A combination of different types of SSI was found in two patients who received operations during period I (3.4\%) and in three patients $(5.2 \%)$ who received operations during period II.

\section{Table 2}

Surgical outcomes

\begin{tabular}{|l|l|l|l|}
\hline & Period I $\mathbf{n = 5 9}$ & Period II $\boldsymbol{n}=\mathbf{5 8}$ & P value* \\
\hline Postoperative complications & $32(54.2)$ & $20(34.5)$ & 0.041 \\
\hline Complication grade $<3$ & $23(39.0)$ & $9(15.5)$ & 0.007 \\
\hline Complication grade $\geq 3$ & $9(15.3)$ & $11(19.0)$ & 0.807 \\
\hline SSI & $24(40.7)$ & $13(22.4)$ & 0.046 \\
\hline Re-operation & $4(6.8)$ & $5(8.6)$ & 0.743 \\
\hline Values in parentheses are percentages & & \\
\hline SSI surgical site infection & & & \\
\hline * Fisher's exact test & & & \\
\hline
\end{tabular}

\section{Table 3}

Grading of surgical complications

\begin{tabular}{|l|l|l|l|}
\hline & Period I $\boldsymbol{n}=\mathbf{5 9}$ & Period II $\boldsymbol{n}=\mathbf{5 8}$ & P value* \\
\hline Grade 1 & $5(8.5)$ & $1(1.7)$ & 0.207 \\
\hline Grade 2 & $18(30.5)$ & $8(13.8)$ & 0.044 \\
\hline Grade 3a & $6(10.2)$ & $5(8.6)$ & 1.000 \\
\hline Grade 3b & $3(5.1)$ & $4(6.9)$ & 0.717 \\
\hline Grade 4a & - & - & - \\
\hline Grade 4b & - & - & - \\
\hline
\end{tabular}


Grade 5

$0(0)$

$2(3.4)$

0.244

Values in parentheses are percentages

* Fisher's exact test

Concentration scores from senior surgeons, which were assessed with a 7-point Likert scale on the psychological questionnaire, were significantly higher during period II than during period I ( $37.5 \%$ for period I vs. $88.9 \%$ for period II; $P=0.033$; Table 4 ). No difference between the two periods was found regarding difficulty of operation, stress during operation, or team collaboration within the surgical team.

\section{Table 4}

Quality of teamwork in the operating room within the surgical team

\begin{tabular}{|c|c|c|c|}
\hline & $\begin{array}{l}\text { Period I } \\
n=16\end{array}$ & $\begin{array}{l}\text { Period II } \\
n=10\end{array}$ & $\begin{array}{l}P \\
\text { value* }\end{array}$ \\
\hline The team ${ }^{\mathrm{a}}$ defined the operation as difficult $\geq 5$ & $9(56.3)$ & $5(50.0)$ & 1.000 \\
\hline $\begin{array}{l}\text { The senior surgeon defined the operation as } \\
\text { difficult } \geq 5^{\mathrm{b}}\end{array}$ & $9(56.3)$ & $7(77.8)$ & 0.401 \\
\hline The team ${ }^{\text {a }}$ defined the operation as stressful $>3$ & $12(75.0)$ & $5(50.0)$ & 0.234 \\
\hline $\begin{array}{l}\text { The senior surgeon defined the operation as } \\
\text { stressful }>3^{b}\end{array}$ & $8(50.0)$ & $3(33.3)$ & 0.677 \\
\hline $\begin{array}{l}\text { The team }{ }^{\mathrm{a}} \text { defined the team collaboration as good } \\
\geq 5\end{array}$ & $15(93.8)$ & $10(100)$ & 1.000 \\
\hline $\begin{array}{l}\text { The senior surgeon defined the team } \\
\text { collaboration as good } \geq 5^{\mathrm{b}}\end{array}$ & $10(62.5)$ & $5(55.6)$ & 1.000 \\
\hline $\begin{array}{l}\text { The team }{ }^{\mathrm{a}} \text { was able to concentrate on the } \\
\text { operation }>4\end{array}$ & $15(93.8)$ & $9(90.0)$ & 1.000 \\
\hline $\begin{array}{l}\text { The senior surgeon was able to concentrate on the } \\
\text { operation }>4^{\mathrm{b}}\end{array}$ & $6(37.5)$ & $8(88.9)$ & 0.033 \\
\hline \multicolumn{4}{|c|}{$\begin{array}{l}\text { Values in parentheses are percentages. Cut-offs represent mean values of each item on a } \\
\text { 7-point Likert scale }\end{array}$} \\
\hline
\end{tabular}


${ }^{\mathrm{b}}$ One missing value in period II

* Fisher's exact test

Median sound levels above baseline during the middle third of each operation were significantly higher during period I than during period II (median $8.85 \mathrm{~dB}$ [range 4.5$11.3 \mathrm{~dB}$ ] vs. $7.17 \mathrm{~dB}$ [range 5.24-9.43 dB]; $P<0.001$; Fig. 1). Median sound levels above baseline during the entire operation (from incision to closure) were not significantly different between the two periods (data not shown). No differences in median sound levels were detected during the first third and the last third of the operation between the two periods (Supplementaryonline supplementary Figs. 1, 2).

\section{Fig. 1}

Mean sound levels above baseline during the middle third of the operations were significantly higher in period I than in period II $(P<0.001$; two-way analysis of variance $[\mathrm{ANOVA}])$

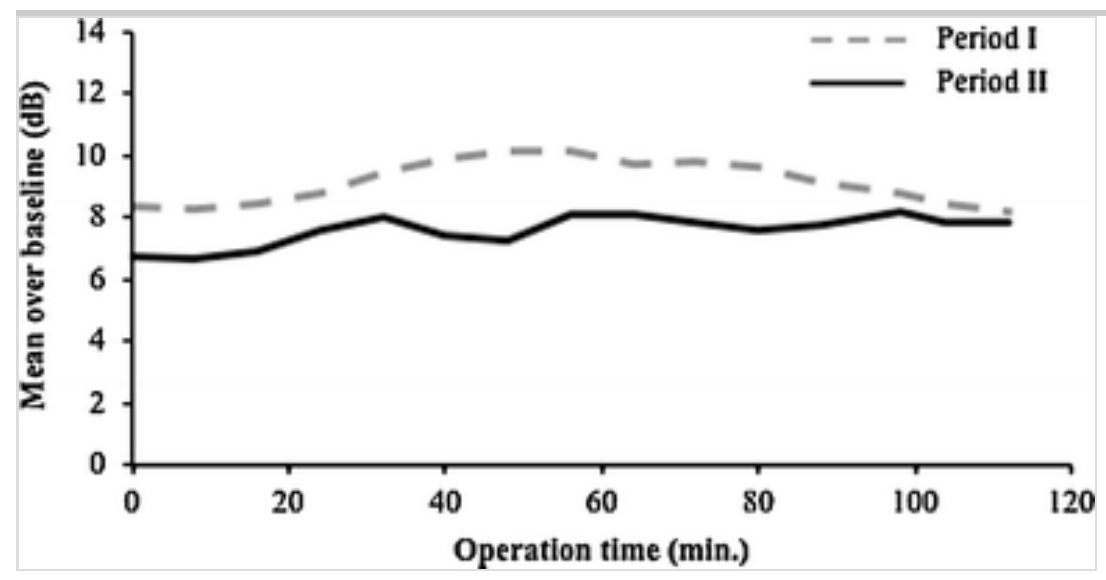

\section{$\mathrm{AQ2}$}

\section{Discussion}

In the present study, working on fellowship teams whose members were more familiar (period II, the last month of the six-month teamwork period) was associated with reduced morbidity after major abdominal surgery.

Team familiarity (enmmon evneriense as team memherc) hac heen found to nlav a 
critical role in good collaboration in the operating room [13, 14]. Working on the same team allows team members to gain mutual experience and to develop routines $[13,14]$. Teams can improve their performance over time, particularly as team members gain experience in collaborating $[13,15]$. Common experience allows teams to perform better work under pressure when operations become more difficult, thereby enabling them to better react to unexpected surgical problems [7, 8]. Previous studies have revealed that working on fixed teams was associated with a shorter duration of operative time, but these analyses did not include patient outcomes [14, 16, 17]. The present study demonstrates the impact of team familiarity on clinically relevant outcome parameters.

The present results are clearly different from the so-called "July effect," in which team performance influences mortality rate throughout the academic year; new residents arrive in July. However, the potential association between resident exchange and mortality rate remains controversial [18-22]. Rather, the July effect may be caused by the introduction of novice residents who are unfamiliar with the clinical workflow, and not a lack of team experience. The present study, however, focused directly on the impact of teamwork experience within surgical teams consisting of senior and junior board-certified surgeons on clinical outcome parameters. Therefore, this study more likely highlights the synergistic effects of cumulative teamwork experience than the lack of experience in the clinical workflow that is expected of residents in their first months of clinical work.

The present study also revealed that the main surgeon's mental concentration was higher in more familiar teams during period II, which may explain the observed effect. In the operating room, distractions that occur in and around the surgical field affect concentration. These distractions can impair surgical performance and result in a higher error rate [23]. Senior surgeons have to deal with various distractions, train junior surgeons, lead the entire surgical team, and simultaneously focus on a complex procedure. Training less-experienced surgeons is a crucial task for senior surgeons. The increase in the knowledge and skills of junior surgeons and the increasing sense of routine in the more experienced teams may enable the senior surgeon to better concentrate on the operation. The lower overall concentration score reported by the main surgeon compared to the entire team further indicates that especially the main 
surgeon is faced with various distractions during the procedure because of the abovementioned additional demands.

Noise in the operating room was previously shown to be associated with an elevated incidence of SSI [4]. The present study recorded lower noise levels in the operating room staffed by familiar teams during the middle third of the operation, which is likely the most difficult part of the entire operation. Low noise levels may indicate smoother teamwork because of more efficient communication, less tension, and a better emotional climate, all of which have been associated with better patient outcome [2]. Obviously, there are many other factors that influence noise levels in the operating room (e.g., doors opening; phones ringing; alarms going off), and very low noise levels may well indicate a cold and uncooperative atmosphere. However, if our observation of an association between team familiarity and noise levels is supported by future studies, and if other influences on noise can be controlled, high noise levels might be considered an indirect, if very gross, indicator of problems in team cooperation.

Breakdown of collaboration in the operating room is relatively frequent and enhances the risk of postoperative complications $[1,2,24]$. Establishing consistent surgical teams for everyday procedures seems to be clinically relevant; team familiarity was previously reported to have a threefold greater impact on the duration of the procedure than the experience of the main surgeon [14]. Team training under artificial situations has been attempted in order to improve surgical performance. However, changes in clinical practice, such as the use of checklists, have been shown to reduce surgical morbidity, often with larger effects than team training $[5,6,25,26]$. Thus, teamwork in surgery may benefit more greatly from structural changes, including the introduction of stable teams, than from additional training.

A strength of the present study is the correlation of team familiarity and other indicators of team behavior with a clinically relevant outcome parameter. Interestingly, mortality and the incidence of severe complications were comparable between the two surgical periods in the present study. These observations cannot be explained by specific patient- or procedure-related issues alone. Low-grade complications seem to be ideal for evaluating team performance, as they are potentially associated with repeated minor breaks or errors in workflow. 
Une of the limitations of the present study 1s 1ts single-center, non-randomized design. In addition, this case-control study investigated only team familiarity between senior and junior surgeons. Team performance in the operating room encompasses various teams, such as the surgical team, the anesthesia team, and the nurses. Additional assessment of teamwork quality and sound measurements were analyzed only in 26 procedures because of the limited availability of specialized work psychologists. The study is also limited by its retrospective design and the limited sample size. Given the results from this study, these limitations warrant a prospective observational trial.

In conclusion, the present investigation has demonstrated the beneficial impact of team familiarity on complication rate, a clinically relevant outcome parameter. This finding may be explained by a scenario in which a senior surgeon operating with a morefamiliar team has a greater ability to concentrate on the operation than a surgeon operating with a less-familiar team. However, this specific finding needs to be confirmed in a prospective fashion that includes the investigation of other teams in other institutions.

\section{Acknowledgments}

This work was supported in part by a grant from the Swiss National Science Foundation (138273).

\section{Conflict of interest}

Drs. Anita Kurmann, Sandra Keller, Franziska Tschan-Semmer, Julia Seelandt, Norbert K. Semmer, Daniel Candinas, and Guido Beldi have no conflicts of interest or financial ties to disclose.

\section{Electronic supplementary material}

Below is the link to the electronic supplementary material.

Mean sound levels above baseline during the first third of the operations showed no significant difference between period I and period II (two-way ANOVA)

Mean sound levels above baseline during the last third of the operations showed no 
significant difference between period I and period II (two-way ANOVA)

\section{References}

1. Gawande AA, Zinner MJ, Studdert DM et al (2003) Analysis of errors reported by surgeons at three teaching hospitals. Surgery 133:614-621

2. Nurok M, Evans LA, Lipsitz S et al (2011) The relationship of the emotional climate of work and threat to patient outcome in a high-volume thoracic surgery operating room team. BMJ Qual Saf 20:237-242

3. Helmreich RL (2000) On error management: lessons from aviation. BMJ 320:781-785

4. Kurmann A, Peter M, Tschan F et al (2011) Adverse effect of noise in the operating theatre on surgical-site infection. Br J Surg 98:1021-1025

5. Neily J, Mills PD, Young-Xu Y et al (2010) Association between implementation of a medical team training program and surgical mortality. JAMA 304:1693-1700

6. Ziewacz JE, Arriaga AF, Bader AM et al (2011) Crisis checklists for the operating room: development and pilot testing. J Am Coll Surg 213(212-217):e210

7. Schraagen JM, Schouten T, Smit M et al (2011) A prospective study of paediatric cardiac surgical microsystems: assessing the relationships between nonroutine events, teamwork and patient outcomes. BMJ Qual Saf 20:599-603

8. Wiegmann DA, El Bardissi AW, Dearani JA et al (2007) Disruptions in surgical flow and their relationship to surgical errors: an exploratory investigation. Surgery 142:658-665

9. National Nosocomial Infections Surveillance (NNIS) System Report, data summary from January 1992 through June 2004 (2004) Am J Infect Control 
$32: 470-485$

10. Haynes AB, Weiser TG, Berry WR et al (2009) A surgical safety checklist to reduce morbidity and mortality in a global population. N Engl J Med 360:491-499

11. Dindo D, Demartines N, Clavien PA (2004) Classification of surgical complications: a new proposal with evaluation in a cohort of 6336 patients and results of a survey. Ann Surg 240:205-213

12. Clavien PA, Barkun J, de Oliveira ML et al (2009) The Clavien-Dindo classification of surgical complications: five-year experience. Ann Surg 250:187196

13. Pisano GP, Bohmer RMJ, Edmondson AC (2001) Organizational differences in rates of learning: evidence from the adoption of minimally invasive cardiac surgery. Manag Sci 47:752-768

14. Elbardissi AW, Duclos A, Rawn JD et al (2013) Cumulative team experience matters more than individual surgeon experience in cardiac surgery. $\mathrm{J}$ Thorac Cardiovasc Surg 145:328-333

15. Harrison DA, Mohammed S, McGrath JE et al (2003) Time matters in team performance: effects of member familiarity, entrainment, and task discontinuity on speed and quality. Pers Psychol 26:633-669

16. Stepaniak PS, Heij C, Buise MP et al (2012) Bariatric surgery with operating room teams that stayed fixed during the day: a multicenter study analyzing the effects on patient outcomes, teamwork and safety climate, and procedure duration. Anesth Analg 115:1384-1392

17. Xu R, Carty MJ, Orgill DP et al (2013) The teaming curve: a longitudinal study of the influence of surgical team familiarity on operative time. Ann Surg 258:953957

18. Phillips DP, Barker GE (2010) A July spike in fatal medication errors: a 
possible effect of new medical residents. J Gen Intern Med 25:774-779

19. Young JQ, Ranji SR, Wachter RM et al (2011) "July effect": impact of the academic year-end changeover on patient outcomes: a systematic review. Ann Intern Med 155:309-315

20. McDonald JS, Clarke MJ, Helm GA et al (2013) The effect of July admission on inpatient outcomes following spinal surgery. J Neurosurg Spine 18:280-288

21. McDonald RJ, Cloft HJ, Kallmes DF (2012) Impact of admission month and hospital teaching status on outcomes in subarachnoid hemorrhage: evidence against the July effect. J Neurosurg 116:157-163

22. Englesbe MJ, Fan Z, Baser O et al (2009) Mortality in Medicare patients undergoing surgery in July in teaching hospitals. Ann Surg 249:871-876

23. Goodell KH, Cao CG, Schwaitzberg SD (2006) Effects of cognitive distraction on performance of laparoscopic surgical tasks. J Laparoendosc Adv Surgl Tech Part A 16:94-98

24. Lingard L, Espin S, Whyte S et al (2004) Communication failures in the operating room: an observational classification of recurrent types and effects. Qual Saf Health Care 13:330-334

25. McCulloch P, Rathbone J, Catchpole K (2011) Interventions to improve teamwork and communications among healthcare staff. Br J Surg 98:469-479

26. Wolf FA, Way LW, Stewart L (2010) The efficacy of medical team training: improved team performance and decreased operating room delays: a detailed analysis of 4863 cases. Ann Surg 252:477-485 